\title{
DeVEloping a NeW ArChitecture to IMPRove ITSM ON CLOUD COMPUTING ENVIRONMENT
}

\author{
Fatemeh Arabalidousti ${ }^{1}$, Ramin Nasiri ${ }^{2}$ and Mahsa razavi Davoudi ${ }^{3}$ \\ 1,2,3 Department of Computer Engineering, Islamic Azad University, Central Tehran \\ Branch, Tehran, Iran
}

\begin{abstract}
Since Cloud Providers Supply Different Types Of Services, It Service Management And The Maturity Of The Infrastructure, Virtualization And Automation Should Be Considered Crucial And Important. Cloud Services Must Be Fully Managed And Designed To Provide Flexible And Reliable Access To Applications, Resources And Services. In This Paper A Comprehensive Cloud Architecture Is Proposed, Which Based On The It Service Management Frameworks, Reference Models And Cloud Architectures To Deliver Better Services In Cloud Computing Environment. This Architecture Reuses Concepts And Techniques Already Exist In A Few Best Itsm Reference Models In Operational Support Services Section Such As Prm-It, Itil V3, Hp And Mof. In Addition Etom's Processes Are Used In Business Support Services For Billing \& Revenue Management Also Cobit5's Process Govern Itsm Of This Architecture In Governance Of It Section. At The Same Time, This Paper Illustrates The Relationship Between Participating Processes. Four Core Cloud Roles Are Defined And In The Last, Five Key Processes That Any Cloud Provider Must Manage, Are Introduced. Finally, The Quality Management Processes Are Presented In Last Section.
\end{abstract}

\section{KEYWORDS}

Cloud Computing Architecture, IT Service Management Frameworks, Reference Model, Cloud Roles, Quality management.

\section{INTRODUCTION}

cloud computing brings along a new IT provisioning model, characterized by keywords like ubiquitous, service-centric, scalable, consumption based and self-service. Cloud computing thus can be defined " $[\ldots]$ as an IT deployment model, based on virtualization, where resources, in terms of infrastructure, applications and data are deployed via the internet as a distributed service by one or several service providers. These services are scalable on demand and can be priced on a pay-per-use basis" [1].

The NIST definition lists three "service models" (software, platform and infrastructure), and four "deployment models" (private, community, public and hybrid) that together categorize ways to deliver cloud services. The definition is intended to serve as a means for broad comparisons of cloud services and deployment strategies, and to provide a baseline for discussion from what is cloud computing to how to best use cloud computing [2].

In the other hand, IT Service Management represents an evolution from managing IT as a technology to managing IT as a business. As businesses move toward On Demand environments, IT organizations are faced with the daunting challenge of increasing the quality of services provided to business, while simultaneously addressing faster rates of change, rising technical complexity, cost pressures, and compliance issues. IT Service Management provides for the DOI : $10.5121 /$ ijccsa.2014.4102 
effective and efficient delivery of IT Services in support of changing business needs. When all of these components come together, they can make IT more efficient and effective [3].

Using of ITSM frameworks, like PRM-IT, ITIL v3, HP, MOF, in cloud environments, which is a service oriented environment, can be quite useful to manage IT services.

In addition, to propose this architecture, cloud computing reference architectures, such as IBM, Oracle, Cisco, HP, NIST are used.

The next section presents related work about cloud and ITSM, and then proposed architecture is introduced.

\section{RELATED WORK}

Different architectures have been presented for cloud computing environment. IBM Cloud Computing Reference Architecture defines the basic elements of cloud computing architecture. This architecture has been structured modularly such that main roles and elements have been defined in the highest level of abstraction [4]. In the NIST Reference Model, there are five main actors: consumers, cloud broker, cloud auditor, cloud carrier and cloud provider .Each actor may be a person or an organization that plays role in transactions or functions available in the cloud [5]. The key components of Oracle architecture are physical resources, cloud builder, cloud application builder, SaaS consumers, cloud management infrastructure and cloud application management. This architecture provides three key perspectives on consumer, provider and broker [6]. HP Cloud System is an integrated system for the management of cloud services across private, public and hybrid clouds. The result of this composition is perfect solution for cloud which can provide cloud driven services for organizations [7]. Cisco has developed the depiction of a cloud reference architecture model, which portrays the architectural layers, connected via APIs and repositories. Cisco's layer are Data center technology architecture, security layer, service orchestration layer, Service delivery and management layer and cloud services consumer layer [8].

There are some papers about ITSM and cloud. A paper of itSMF Deutschland e.V. postulates that there can be no cloud computing without ITSM [9]. Cloud computing allows to establish a new provisioning model for IT and IT services [1]. Therefore, it can be assumed that the common ITSM has to change or to self-propagate respectively. During the second half of the 20th century, increasing importance of Information Technology (IT) for business processes required a process- and service-oriented IT service-delivery [10], Therefore different approaches for effective and efficient IT provisioning have been developed. Some of them are established as best practices [11]. ITSM thus stands for a process to plan and to control the quality and quantity of provided IT services considering the objectives of business processes, customer orientation and cost optimization [10] and can be defined as "[...] a set of specialized organizational capabilities for providing value to customers in the form of services" [12]. A collection of best practices in ITSM, the Information Technology Infrastructure Library (ITIL), established as so called de-facto-standard in service oriented IT management [13]. While ITIL was first published in 1989 by Central Computer and Telecommunications Agency (CCTA) and recently the second revision of version 3 was released by the Office of Government Commerce (OGC) [14], the term "cloud computing" has been used only recently in scientific publications. "IT can be seen as the consequent evolution of the traditional on-premise computing spanning outsourcing stages from total to the selective, and from the multi-vendor outsourcing to an asset-free delivery" [15]. 
there are a lot of publications focusing on special aspects in ITSM in cloud Environments. Mapping to the ITSM-processes according to the ITIL v3 standard, most of the publications are about service level management (SLM), information security management (SEC), service desk, incident and problem management (INC, PRO), service asset \& configuration management (CFG) and change management. Actually ITIL v3 defines approximately 26 processes and functions [16].

PRM-IT, IBM Process Reference Model, is an overall view of the processes involved in the information technology management. This model was proposed by IBM in 2008[17].

Microsoft Operations Framework (MOF) was introduced in 2008, which manages IT services in 3 main phases and 1 managerial layer [18]. HP IT Service Management Reference Model is composed of five services, which was published in 2000[19].

\section{PROPOSED ARCHITECTURE}

Proposed Architecture is composed of IT service Management process based on best practices, including PRM-IT, ITIL v3, Cobit5 and eTOM [20]. This architecture gives Cloud Provider the ability to significantly improve efficiency and effectiveness. This paper enables to easily understand processes, the relationships between process, and the roles involved in an efficient process implementation.

According to different mappings between ITIL v3, PRM-IT, HP and MOF, PRM-IT has been chosen as a comprehensive reference model for the proposed architecture [20]. This architecture uses eTOM processes associated with bills management [21]. COBIT5 has been considered as a comprehensive governance framework in architecture because it is a robust business framework for management and governance of IT organizations [22]. Therefore, its governance processes are used in this architecture. Figure 1 shows the proposed architecture.

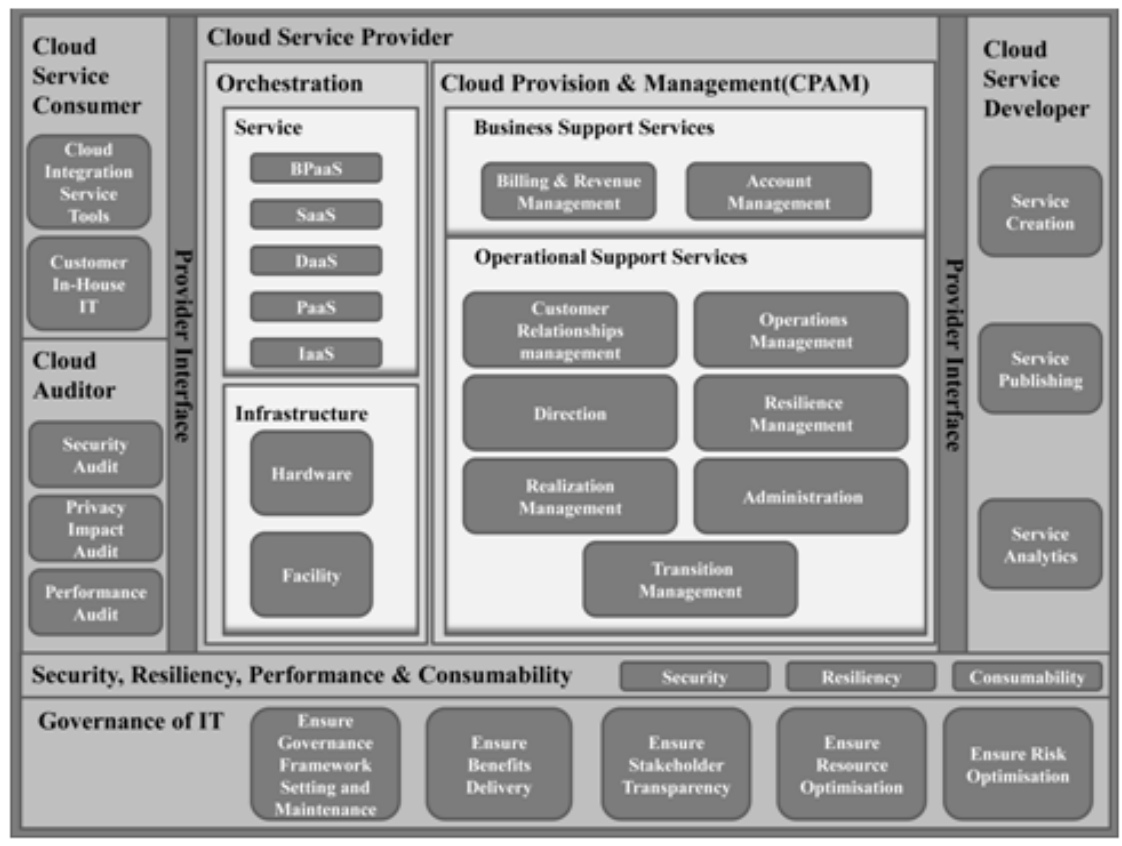

Figure 1. The Proposed Architecture Model 
In this paper, the proposed architecture focuses on all potential activities that could occur within the Governance of IT and CPAM. Service provider, Service developer, consumer, User, supplier and Business are working based on processes of Governance and CPAM. Comprehensive and effective activity sets in this architecture are shown in figure 2 .

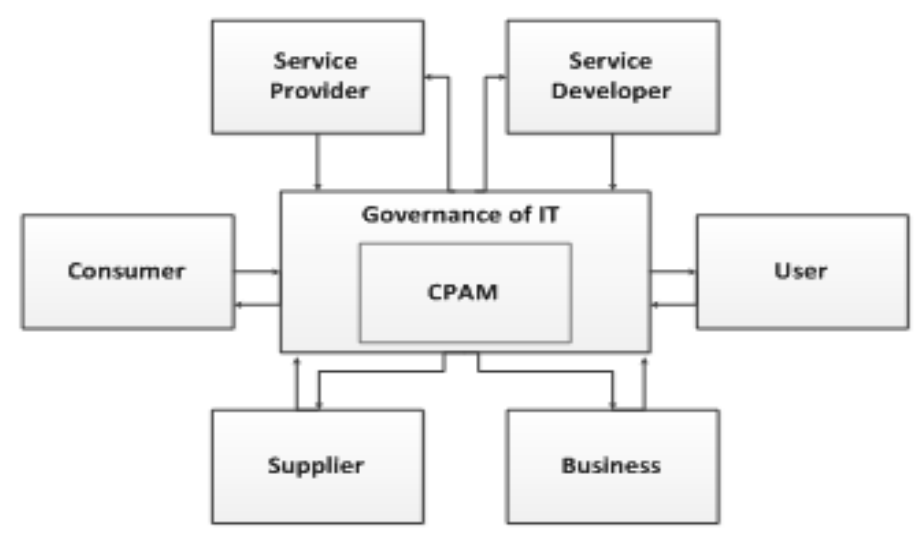

Figure 2. Cloud Activities Set

This architecture contains the following resources:

\subsection{Cloud Process}

A structured set of activities designed to accomplish a specific objective. A process may include any of the roles, responsibilities, tools and management controls required to reliably deliver the outputs [3].

This processes described within Proposed Architecture are closely aligned with PRM-IT, ITIL v3, Cobit5 and eTOM. While IT reference models like ITIL provide high-level guidance for what should be implemented, PRM-IT offers detailed process guidance for all activities.

\subsection{Cloud Roles}

A role is an abstract definition of a set of responsibilities that encompass tasks to be performed and work products to be produced [3]. In the proposed architecture, there are 4 types of major roles:

This Architecture proposes four core cloud roles - Cloud service developer, Cloud service provider, Cloud service consumer and Cloud auditor- supplemented with several sub-roles as can be seen in figure 3 . 


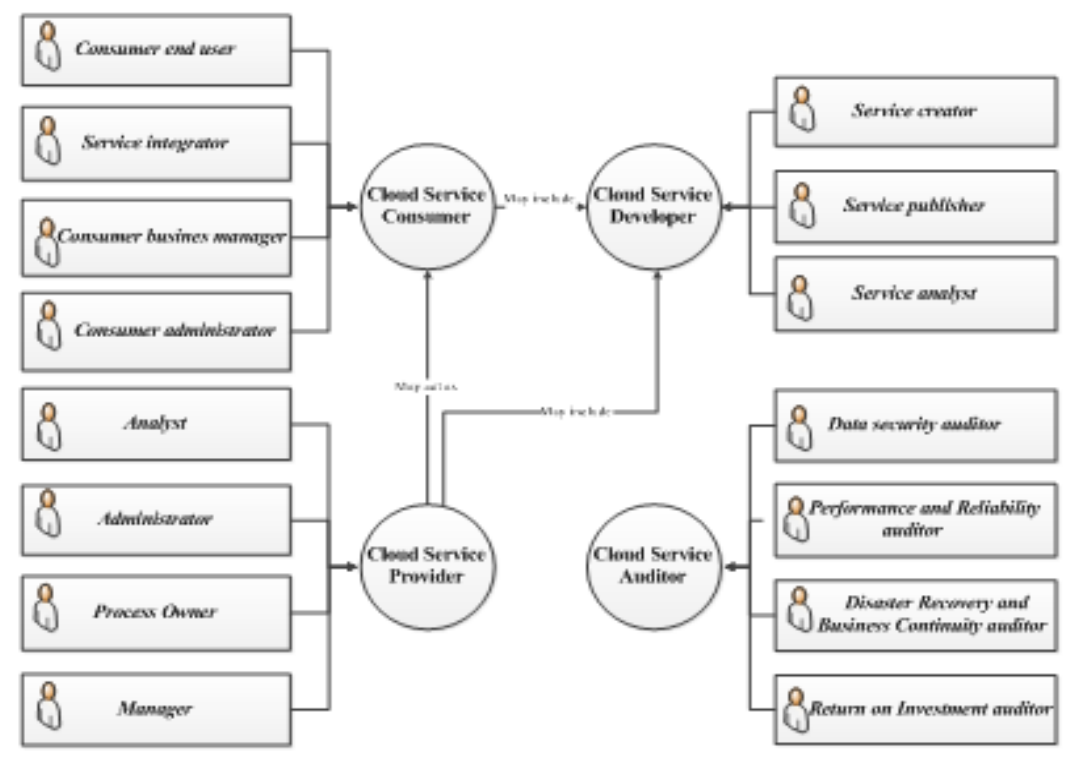

Figure 3. Major roles

The generic roles that are referenced by the specific roles assigned to the various processes in Cloud provider.

There are three types of generic roles in CPAM part:

Cloud Process Administrator: The Process Administrator supports the Process Manager by managing records, tracking action items, and providing process-related reports [3].

Cloud Process Manager: The Process Manager performs the day-to-day overall management of the process. This role ensures that all process activities are being performed and that they are staffed adequately [3].

Cloud Process Owner: The Process Owner is the sponsor of the process, and holds the responsibility and executive authority for the overall process results across the enterprise [3].

\section{DETAILED ARCHITECTURE COMPONENTS}

\subsection{Architecture Components in cloud Service Provider Section}

\subsubsection{Service Orchestration}

Service Orchestration refers to the composition of system components to support the Cloud Providers activities in arrangement, coordination and management of computing resources in order to provide cloud services to Cloud Consumers [5].

This section composed of two parts:

Services: All services of cloud are delivered in this part by cloud provider. (Infrastructure-as-aService, Platform-as-a-Service, Software-as-a-Service, Business-Process-as-a-Service, Data Storage-as-a-Service) $[4,5]$. 
Infrastructure: This layer includes all the physical computing resources. It has two elements. Hardware and Facility [5].

\subsubsection{Cloud Provision and Management(CPAM)}

This part exposes a set of business and operational management focused services. These functions must be exploited by Cloud Services to run within the context of the respective cloud service provider.

\subsubsection{Businesses Support Services}

Business Support Services represents the set of business-related services, which are needed by Cloud Service Developer to implement a cloud service. Figure 4 shows Details of Business Support Services in the Proposed Architecture Model.

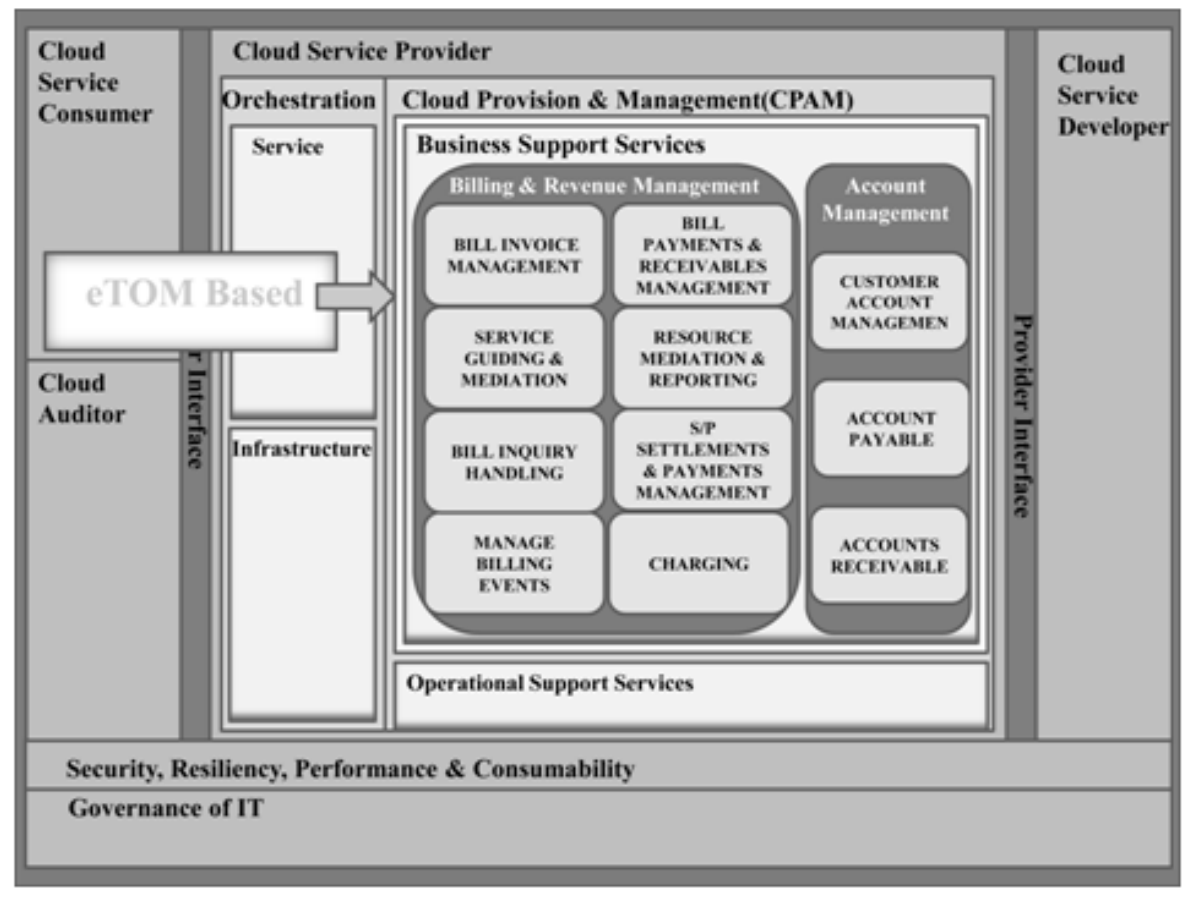

Figure 4. Details of Business Support Services in the Proposed Architecture Model

\subsection{Account Management:}

This section is part of the IBM architecture model and describes the processes involved in managing of client accounts $[4,20]$.

\subsection{Billing and Revenue Management:}

This section is responsible for the collection of appropriate usage records, determining charging and billing information, production of timely and accurate bills, for providing pre-bill use information and billing to customers, for processing their payments, and performing payment collections, These processes are part of the eTOM process framework [20, 21]. 


\section{Process}

This process category is composed of these processes:

- Bill Invoice Management

Ensure the bill invoice is created, physically and/or electronically produced and distributed To customers, and that the appropriate taxes, discounts, adjustments, rebates and credits For the products and services delivered to customers have been applied [21].

- Service Guiding \& Mediation

Manage usage events by correlating and formatting them into a useful format as well as Guiding them to an appropriate service [21].

- Bill Inquiry Handling

Ensure the timely and effective fulfillment of all customer bill inquiries and complaints Manage Billing Events [21].

- Charging

The purpose of Charging is to assign a value (monetary or other) to an event or product, Or combination [21].

- Bill Payments \& Receivables Management

Ensure that enterprise revenue is collected through pre-established collection channels and put in place procedures to recover past due payments [21].

- Resource Mediation \& Reporting

Manage resource events by correlating and formatting them into a useful format [21].

- S/P Settlements \& Payments Management

S/P Settlements \& Payments Management processes manage all settlements and payments for the enterprise, including invoice validation and verification and payment authorization [21].

- Manage Billing Events

The billing events management processes encompass the functions required to guide, distribute, mediate, summarize, accumulate, and analyze billing event records [21].

\subsubsection{Operational Support Services}

This section represents the operational management and technical-related services, which are needed by Cloud Service Developer to implement a cloud service [20]. These services use PRMIT Reference Model process. PRM-IT may be selected among other frameworks such as ITIL v3, $\mathrm{HP}, \mathrm{MOF}$ as a more complete reference and used set forth in the operational section of the proposed architecture [20].

Figure 5 shows Details of Operational Support Services the Proposed Architecture Model. 


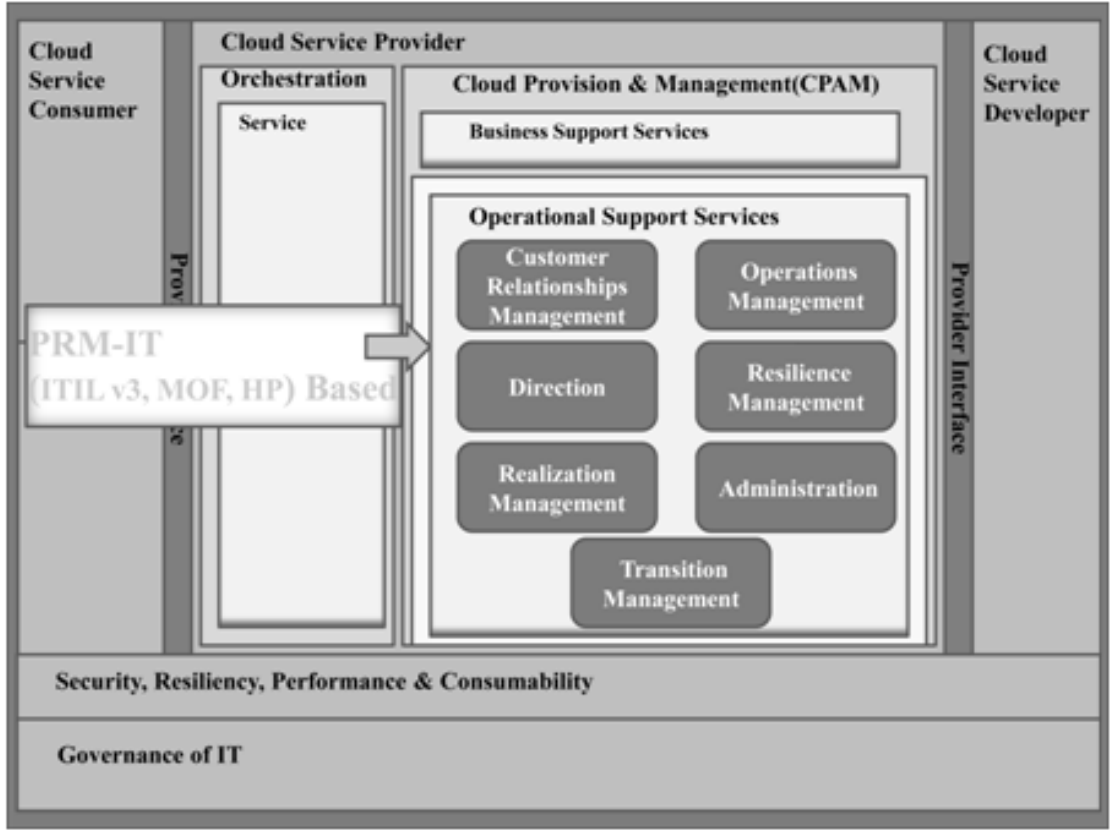

Figure 5. Details of Operational Support Services the Proposed Architecture Model

\subsection{Customer relationships Management}

The Customer Relationships process category gives IT service providers a mechanism to understand, monitor, perform and compete effectively in the marketplace they serve [17].

\section{Processes}

This process category is composed of these processes:

- Service Marketing and Sales

The process is Marketing IT services to IT customers [17].

- Service Catalog Management

The purpose of the Service Catalog Management process is to provide an authoritative source of consistent information on all agreed services and ensure that it is widely accessible to those who are approved to view this information. [17].

- Service Level Management

Service Level Management is the process of negotiating, defining, measuring, managing and improving the quality of IT services at an acceptable cost [17].

- Demand Management

The purpose of the IT Demand Management process is to manage the demand for IT services [17].

- IT Customer Transformation Management

The purpose of the IT Customer Transformation Management process is to assist customers in the transformation of their business throughout the life cycle [17].

- Customer Satisfaction Management

The purpose of the Customer Satisfaction Management process is measuring how satisfied customers are with IT services [17]. 
Figure 6 shows the relationship between Customer Relationships Management process category and other process category.

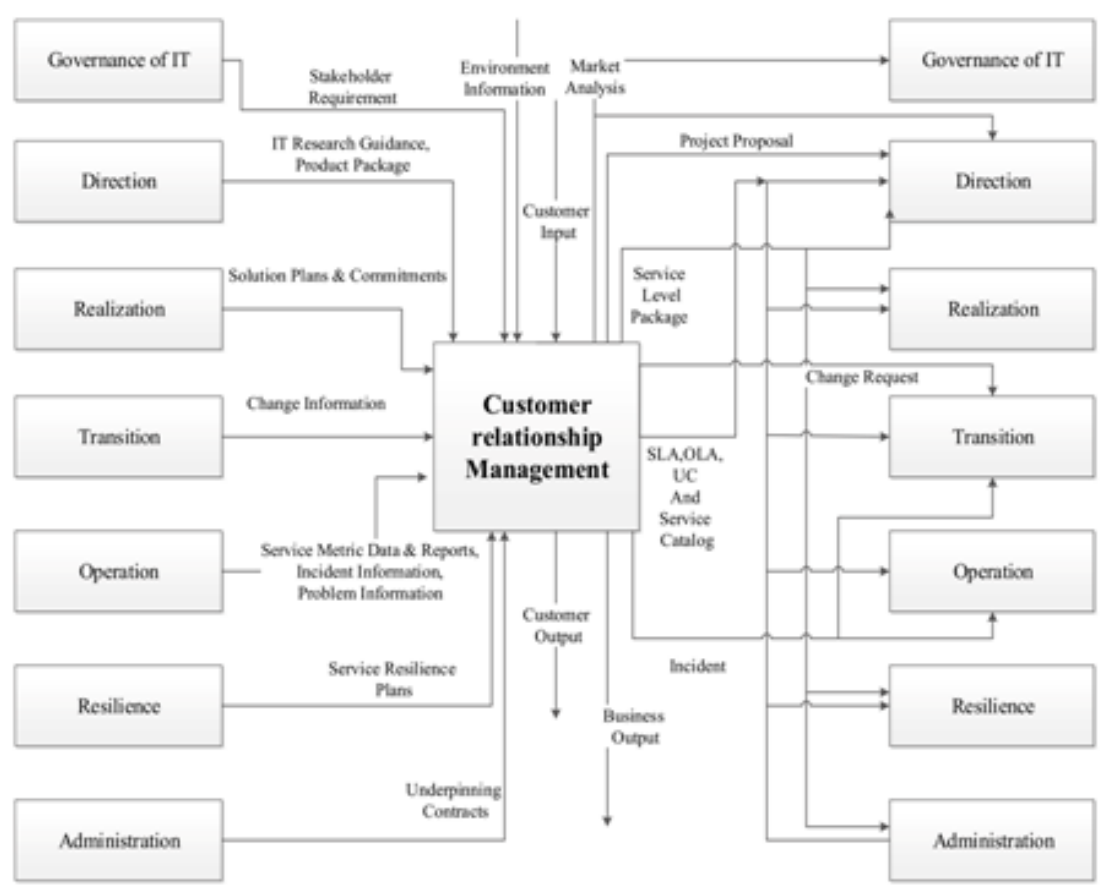

Figure 6. Relationship between Customer Relationships Management process category and other process category

\subsection{Direction}

The Direction process category aligns the IT outcomes to support the business strategy, minimizes risk exposures, and manages the IT Architecture and IT Portfolio [17].

\section{Processes}

This process category is composed of these processes:

- $\quad$ IT Strategy

The purpose of the IT Strategy process is to determine the overall direction of the IT organization [17].

- IT Research and Innovation

The IT Research and Innovation process exists to identify new IT technology trends [17].

- Architecture Management

The Architecture Management process exists to create, maintain, promote and govern the use of IT architecture models and standards, across and within business change programs [17].

- $\quad$ Product Management

Product Management is the management of an IT product through its lifecycle [17].

- Portfolio Management

The purpose of the Portfolio Management process is to manage the set of all IT projects and initiatives [17]. 
- $\quad$ Program and Project Management

The purpose of Program and Project Management is to manage IT development and other projects [17].

Figure 7 shows the relationship between Direction process category and other process category.

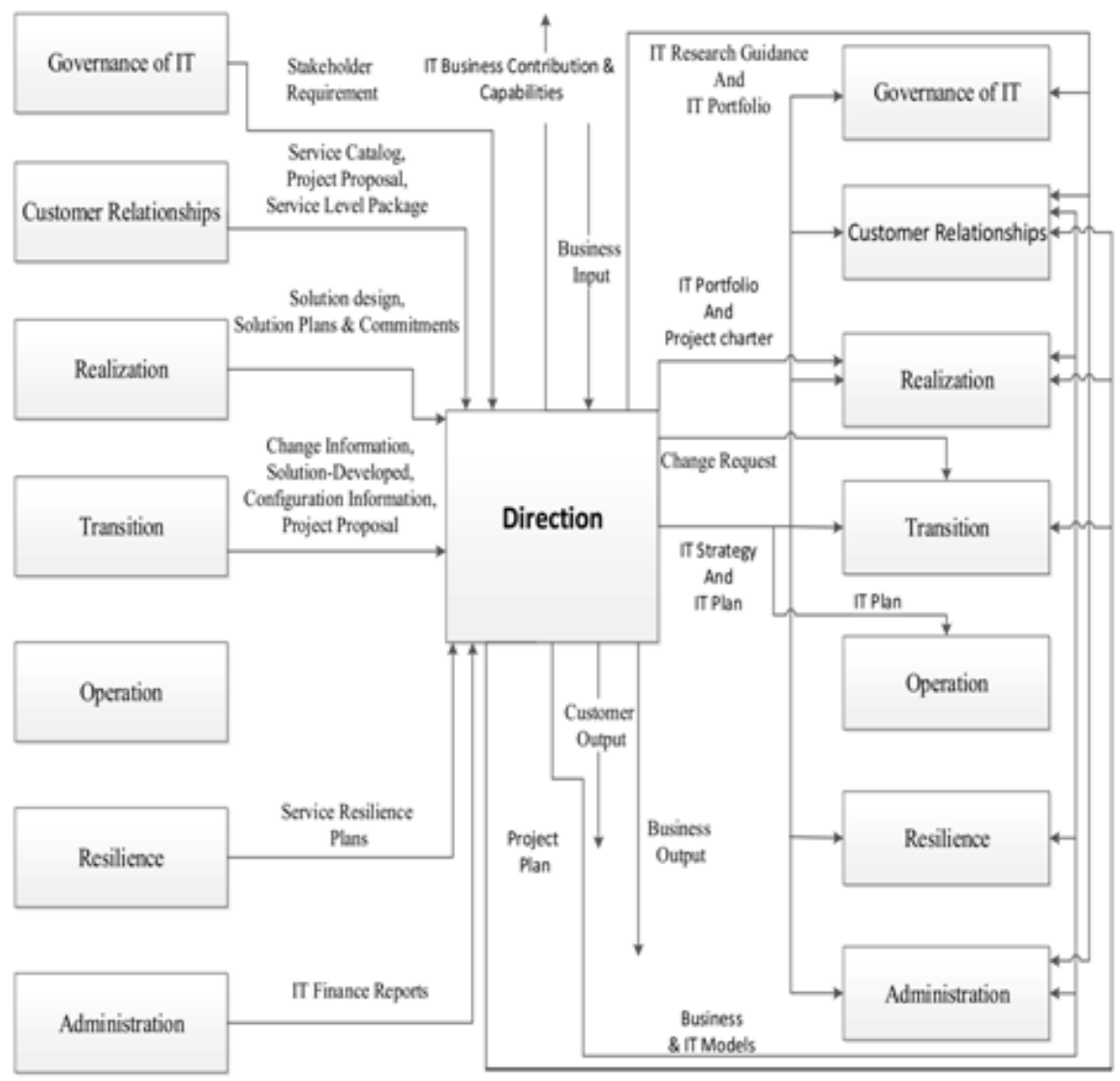

Figure 7. Relationship between Direction process category and other process category

\subsection{Realization Management}

The Realization process category exists to create solutions that will satisfy the requirements of IT customers and stakeholders, including both the development of new solutions and the enhancements or maintenance of existing ones [17].

\section{Processes}

This process category is composed of these processes:

- Solution Requirements

This process focuses on Identifying and specifying IT solution requirements [17].

- Solution Analysis and Design

The Solution Analysis and Design process exists to create a fully documented design from the agreed solution requirements, describing the behaviour of solution elements, the acceptance criteria, and agreed measurements [17].

- Solution Development and Integration 
The Solution Development and Integration process exists to bring together all of the elements specified by the solution design [17].

- Solution Test

The Solution Test process exists to validate prior to deployment that the solution and its features conform to design specifications and requirements [17].

- Solution Acceptance

The purpose of the Solution Acceptance process is to validate that the proposed solution, either as individual artefacts or in its complete form, meets acceptance criteria at defined checkpoints [17]. Figure 8 shows the relationship between Realization process category and other process category.

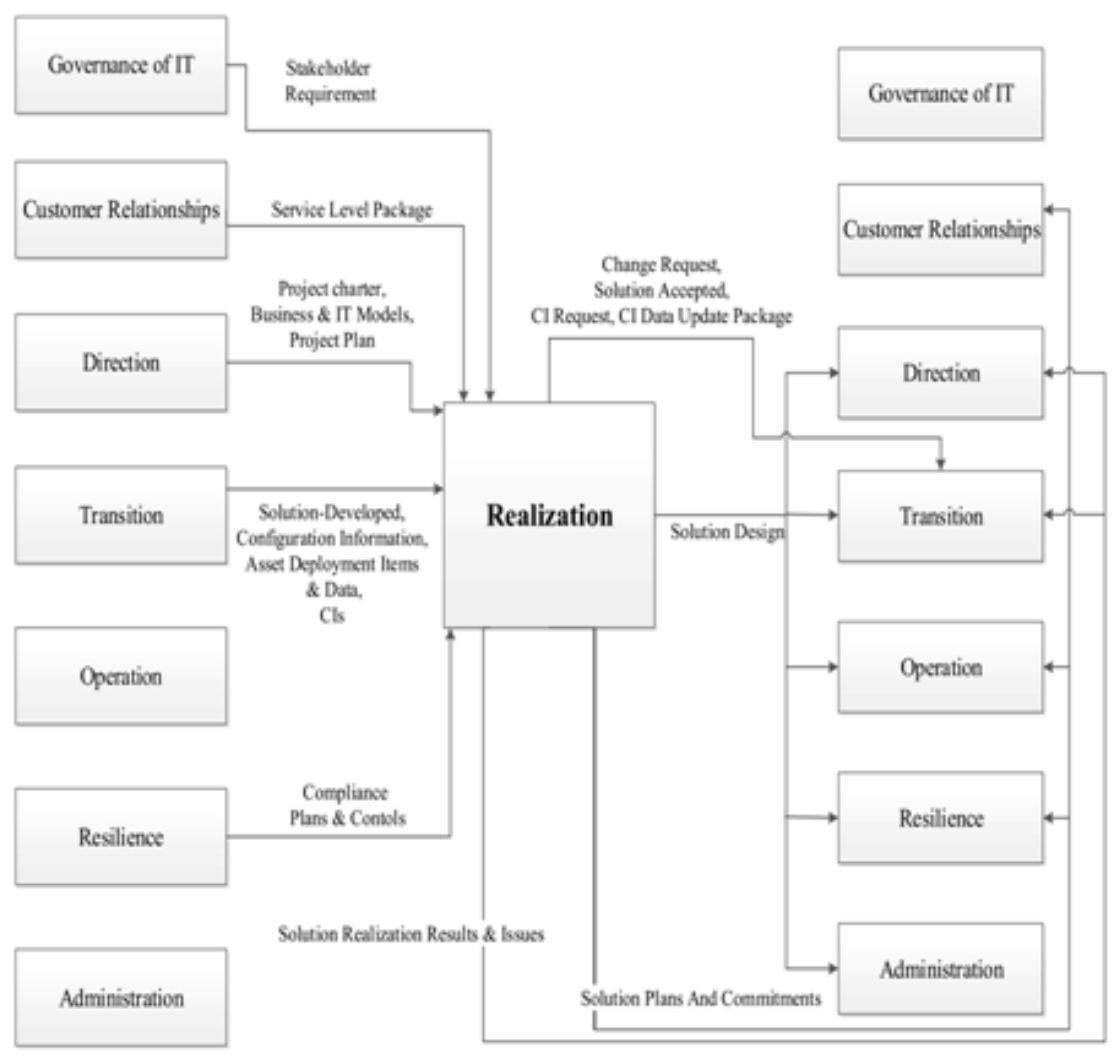

Figure 8. Relationship between Realization process category and other process category

\subsection{Transition Management}

The Transition category of processes exists to support any aspect related to a life cycle status change in solutions and services [17].

\section{Processes}

This process category is composed of these processes:

- Change Management

Change Management typically begins with the creation of a Change Request (RFC). The change request documents details of the proposed change in order to support a range of business and 
technical assessments, leading to approval (or rejection) and ultimately to application of the change [17].

- Release Management

The purpose of the Release Management process is to prepare and finalize release packages [17].

- Deployment Management

The purpose of the Deployment Management process is to place releases and other desired changes into their target environments [17].

- Configuration Management

Configuration Management identifies, controls, and maintains all elements in the IT infrastructure called Configuration Items [17].

- Asset Management

Asset Management is to account for and manage all IT assets in the enterprise, throughout all stages of their lifecycle [17].

Figure 9 shows the relationship between Transition process category and other process category.

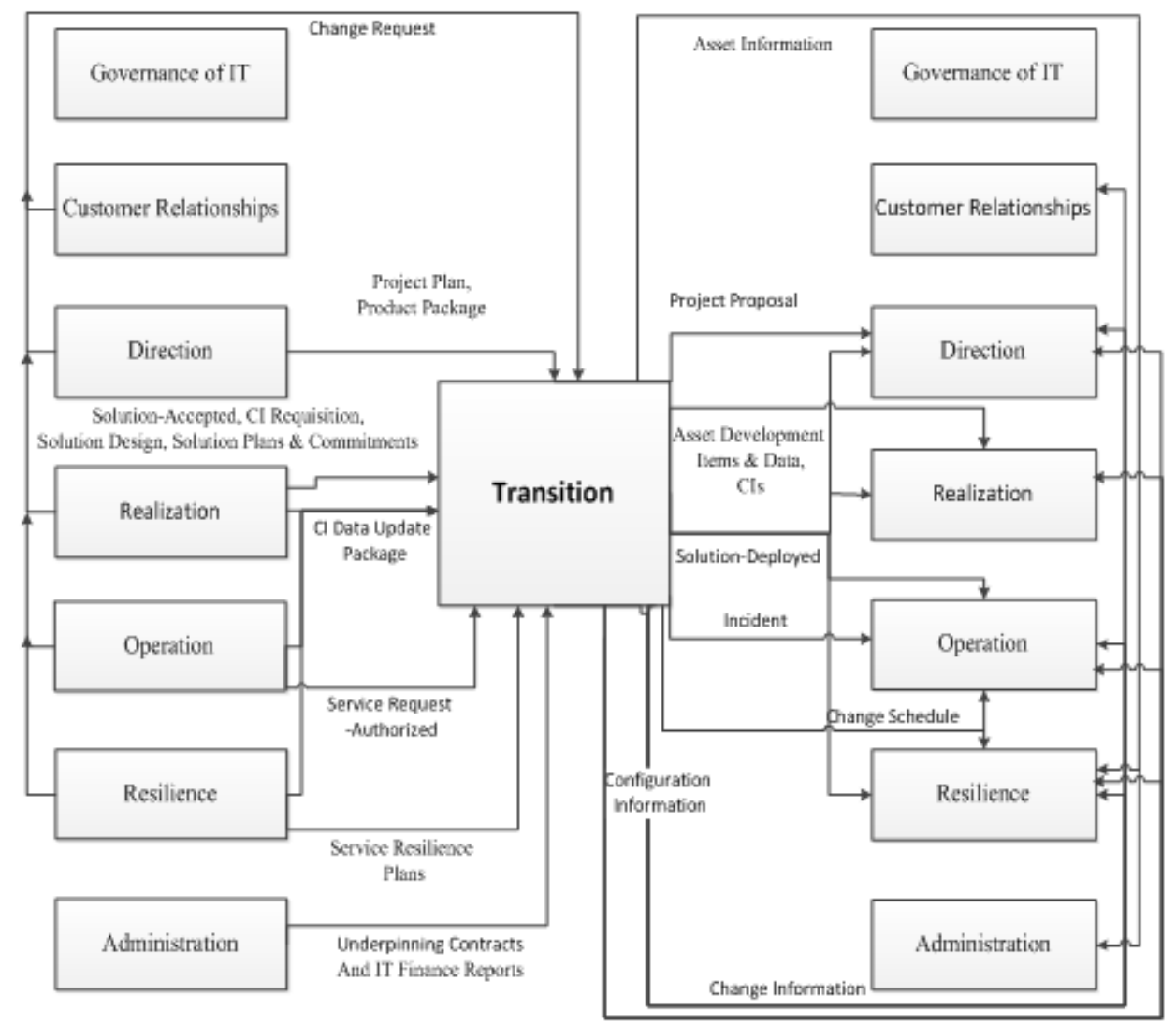

Figure 9. Relationship between Transition process category and other process category

\subsection{Operation Management}

This category contains the operational service processes that enable daily IT activities using available infrastructure, applications, and services to meet service level agreements (SLAs) and business objectives [17]. 


\section{Processes}

This process category is composed of these processes:

- Request Fulfillment

Request Fulfilment is the initial support handling of contact with IT users [17].

- Service Execution

Service Execution is the actual delivery of a service to IT users [17].

- Data Management

Data Management oversees data lifecycles as well as backups and restores [17].

- Event Management

The purpose of the Event Management process is to identify and prioritize infrastructure, service, business process and security events, and to establish the appropriate response to those events, especially responding to conditions that could lead to potential faults or incidents. [17].

- Incident Management

Incident Management provides rapid response to possible service disruptions [17].

- Problem Management

Problem Management identifies and resolves the root causes of service disruptions [17].

Figure 10 shows the relationship between Operation process category and other process category.

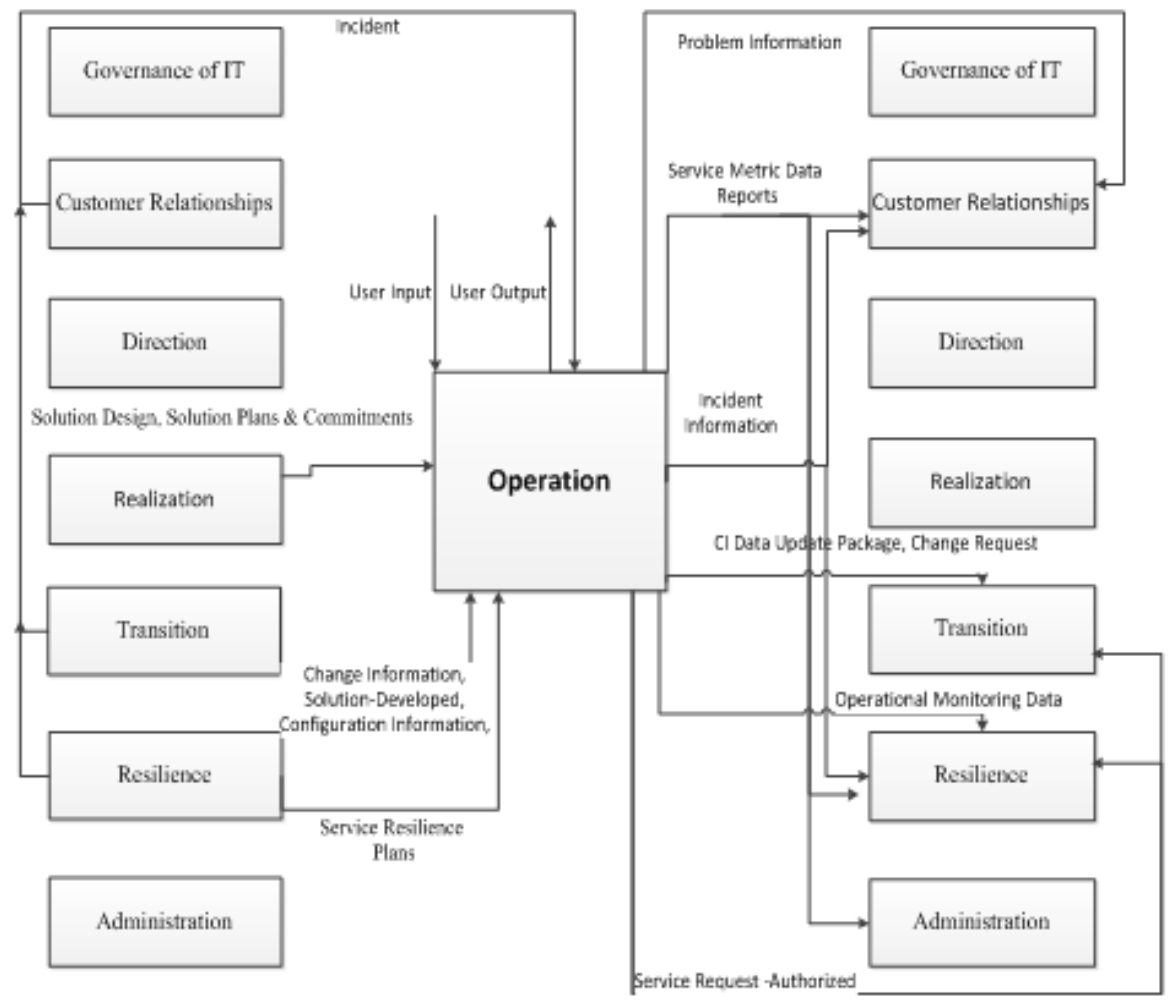

Figure 10. Relationship between Operation process category and other process category

\subsection{Resilience Management}

The Resilience category of processes describes the analysis and proactive planning required enabling resilient infrastructure, applications, and services [17]. 


\section{Processes}

This process category is composed of these processes:

- Compliance Management

The purpose of the Compliance Management process is to ensure adherence to laws and regulations, internal policies, procedures, and stakeholder commitments [17].

- Availability Management

The purpose of Availability Management is to match the availability of the IT services against the current and future identified needs of the business or to exceed them [17].

- $\quad$ Capacity Management

The purpose of Capacity Management is to match the capacity of the IT services and infrastructure to the current and future identified needs of the business [17].

- Facilities Management

The purpose of the Facilities Management process is to create and maintain a physical environment that houses IT resources and to optimize the capabilities and cost of that environment [17].

- IT Service Continuity Management

The purpose of the Service Continuity Management process is to ensure that agreed IT services will support business requirements in the event of a disruption to the business, based on the committed recovery schedule [17].

Figure 11 shows the relationship between Resilience process category and other process category. 


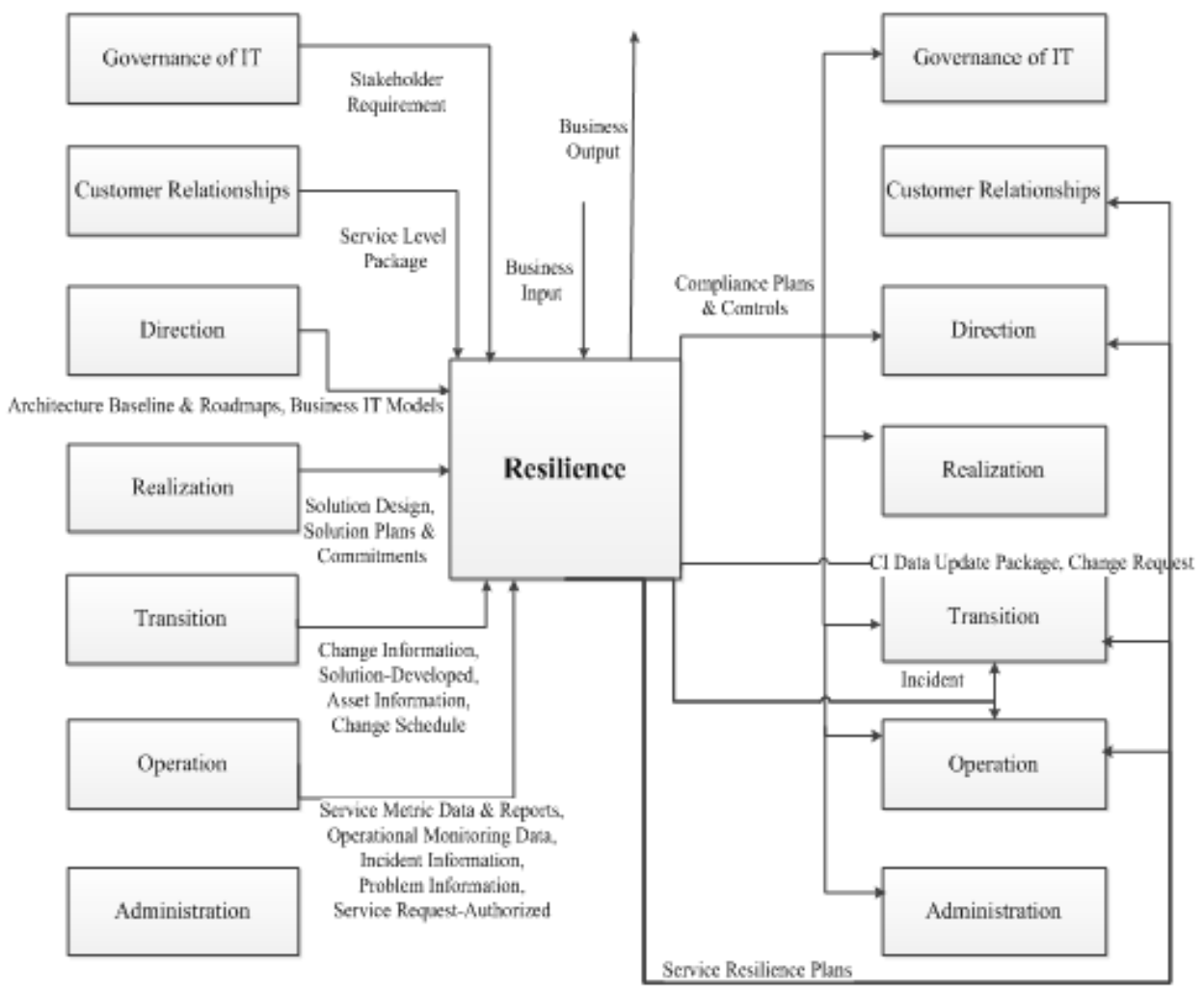

Figure 11. Relationship between Resilience process category and other process category

\subsection{Administration}

The Administration process category brings together the processes that look after many of the non-technical resources: people, finances, and contracts, among others that support IT service delivery [17].

\section{Processes}

This process category is composed of these processes:

- Financial Management

Financial Management aims to assist the internal IT organization with the cost-effective management of the IT resources required for the provision of IT services [17].

- Supplier Management

The purpose of the Supplier Management process is to manage interactions with suppliers and partners formally by selecting them based on their ability [17].

- Service Pricing and Contract Administration

The purpose of the Service Pricing and Contract Administration process is to establish a pricing mechanism for the IT entity to sell its services [17].

- Workforce Management

The purpose of the Workforce Management process is to provide the optimal mix of staffing (resources and skills) in order to deliver the agreed IT services at the negotiated service levels and Commitments [17]. 
- Knowledge Management

The purpose of the Knowledge Management process is to Capture and manage IT intellectual capital [17].

Figure 12 shows the relationship between Resilience Administration process category and other process category.

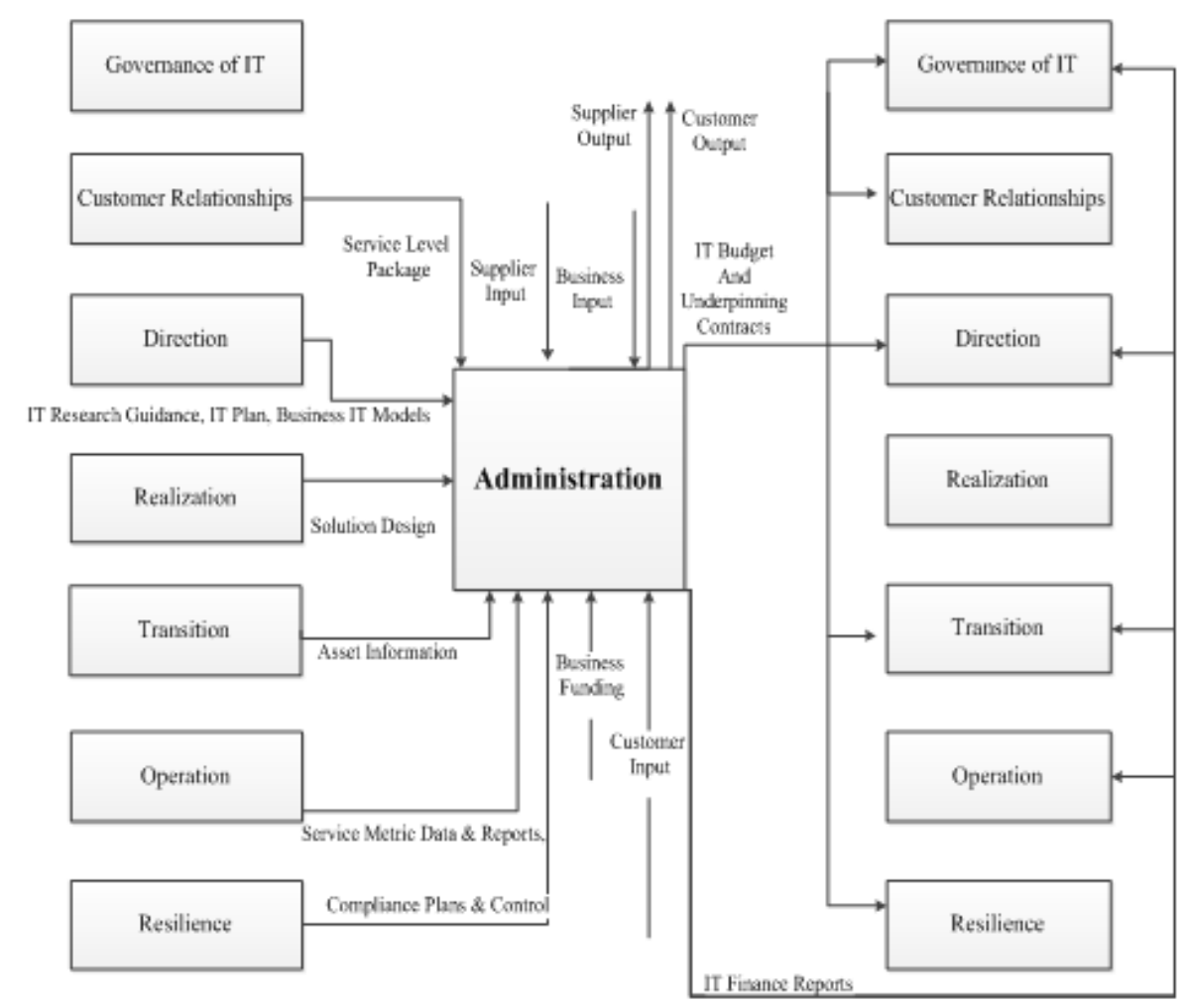

Figure 12. Relationship between Administration process category and other process category

\subsection{Architectural Components in cloud Service Consumer Section}

\subsubsection{Cloud Service Integration Tools}

These tools integrate cloud services for consumer [4].

\subsubsection{Consumer In-house IT}

Consumer In-house IT should be integrated with cloud services consumed from a cloud service provider, the aforementioned cloud service integration tools are required [4].

\subsection{Architectural Components in cloud Service Developer Section}

The service developer creates, publishes and monitors the cloud service. This section includes three parts. Development environments for service creation vary. If developers are creating a SaaS application, they are most likely writing code for an environment hosted by a cloud provider [5]. 


\subsubsection{Service Creation}

Developers create cloud services [5].

\subsubsection{Service publishing}

Cloud services, will be published by the developers [5].

\subsubsection{Service Analytics}

During service creation, analytics involve remote debugging to test the service before it is published to consumers [20]. Once the service is published, analytics allow developers to monitor the performance of their service and make changes as necessary [5].

\subsection{Architectural Components in cloud Auditor Section}

A cloud auditor is a party that can perform an independent examination of cloud service controls with the intent to express an opinion thereon. Audits are performed to verify conformance to standards through review of objective evidence [5].

This section has three parts:

\subsubsection{Security Audit}

A cloud auditor can make an assessment of the security controls in the information system to determine the extent to which the controls are implemented correctly, operating as intended, and producing the desired outcome with respect to the security requirements for the system [5].

\subsubsection{Privacy Impact Audit}

A privacy impact audit can help organization comply with applicable privacy laws and regulations governing an individual's privacy, and to ensure confidentiality and integrity[5].

\subsubsection{Performance Audit}

To evaluate the performance takes place [5].

\subsection{Security, Resiliency, Performance \& Consumability}

These non-functional aspects must be viewed from an end-to-end perspective including the structure of architecture by itself, the way the hardware infrastructure is set up (e.g. in terms of isolation, network zoning setup, data center setup for disaster recovery, etc.) and how the cloud services are implemented[10].

\subsection{Governance of IT}

Deal with the stakeholder governance objectives-value delivery, risk optimisation and resource optimisation-and include practices and activities aimed at evaluating strategic options, providing direction to IT and monitoring the outcome [22]. This domain contains five governance components and uses COBIT5's processes Figure 13 shows Relationship between Governance of IT category and other process category 


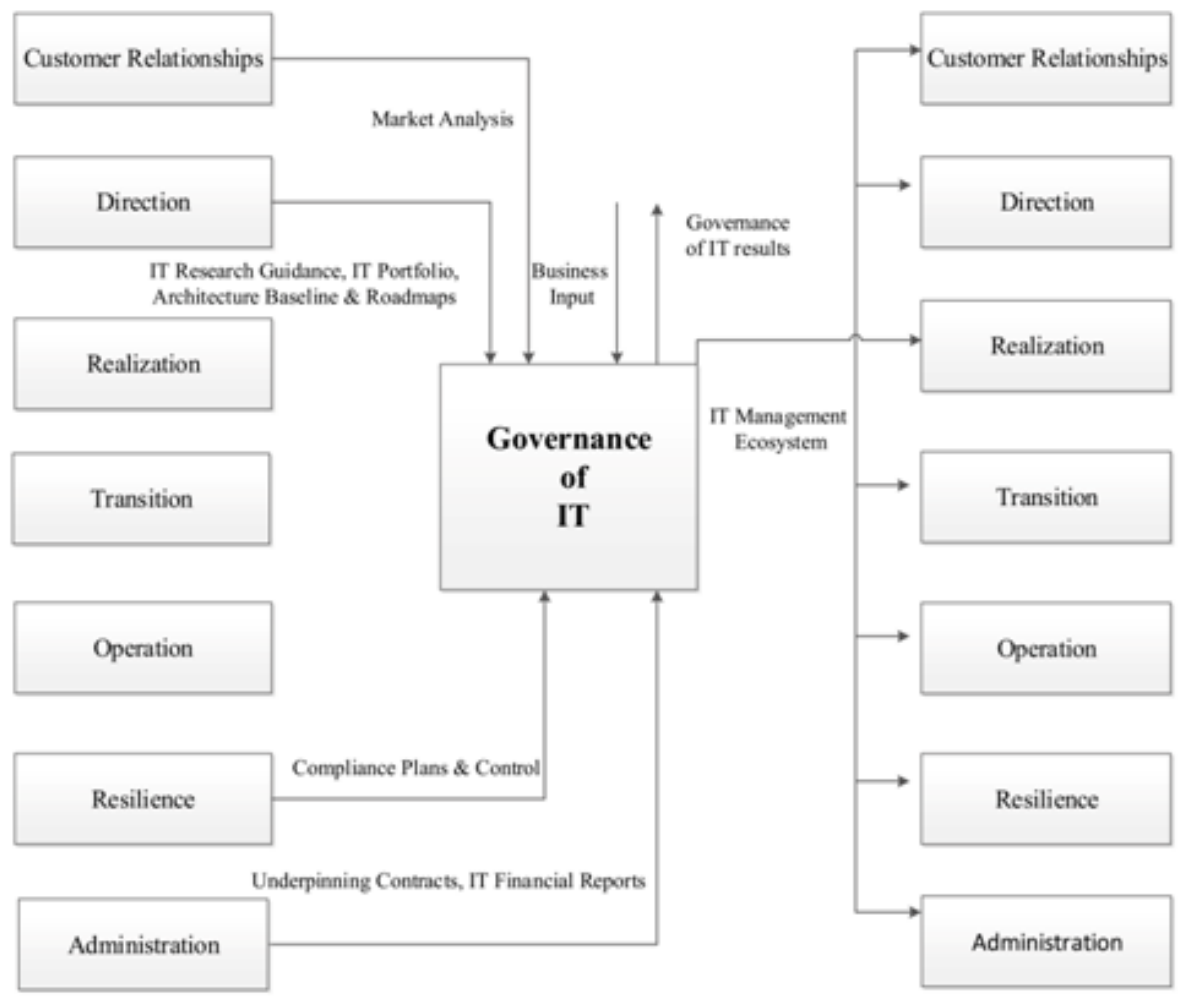

Figure 13. Relationship between Governance of IT category and other process category

\subsubsection{Ensure Governance Framework Setting and Maintenance}

Analyse and articulate the requirements for the governance of enterprise IT, and put in place and maintain effective enabling structures, principles, processes and practices, with clarity of responsibilities and authority to achieve the enterprise's mission, goals and objectives [22].

\subsubsection{Ensure Benefits Delivery}

Optimise the value contribution to the business from the business processes, IT services and IT assets resulting from investments made by IT at acceptable costs [22].

\subsubsection{Ensure Risk Optimisation}

Ensure that the enterprise's risk appetite and tolerance are understood, articulated and communicated, and that risk to enterprise value related to the use of IT is identified and managed [22].

\subsubsection{Ensure Resource Optimisation}

Ensure that adequate and sufficient IT-related capabilities (people, process and technology) are available to support enterprise objectives effectively at optimal cost [22]. 


\subsubsection{Ensure Stakeholder Transparency}

Ensure that enterprise IT performance and conformance measurement and reporting are transparent, with stakeholders approving the goals and metrics and the necessary remedial actions [22].

\section{FIVE KEY PROCESSES OF ITSM}

Implement of all the processes have a large overload. So some organization cannot implement all of them. In this situation, at least five key processes must be implemented: Incident management, problem management, Change management, Configuration management and service Level management.

The traditional ITSM processes rely on a central CMDB. Looking to a cloud environment, configuration items (CI) are distributed across a numerous service providers and there is no single-point-of-truth. Thus the approach of a central CMDB does not work in a crossdomain or cross-provider environment. Especially the lack in notion of dependency of one CI on another seems to be an actual challenge. Given these pre-conditions, Wassermann et al. (2009) respectively Ludwig et al. (2009) designed the "Distributed Configuration Management" (DCM) and "Smart

Configuration Items" (SCI) which can be exposed to other domains using a defined interface based on Representational State Transfer (REST), IBMs Web Sphere sMash, Mashups and AJAX [23].

There is very legitimate need for a clear and formal methodology to handle SLAs in the context of cloud computing. WSLA, which suggests very flexible architecture for managing SLAs between providers and consumers, seem to be the most suitable candidate. In applying WSLA however, the need for a host of support services arises. Some cloud computing providers may provide these support services but WSLA does not strictly mandate such provisions and hence third parties can step into provide the necessary services. We see this as one of the strong points of WSLA where, true to the paradigm of SOA, every functionality is provided as a service that may not necessarily come from the same provider [24].

Problem management has the dual goals of minimizing the adverse impact of errors within the IT infrastructure, and preventing the recurrence of incidents related to those errors and classes of those errors. However, many organizations believe they have implemented problem management when in reality they may have only become better at managing incidents. These organizations do not fully execute or manage all facets of problem management and therefore do not realize its full benefits [25].

\section{Quality management of proposal architecture}

Quality Management ensures the quality of all IT products and services. This process focuses on assuring that specific work outcomes are of a high quality. This applied process includes workflow from Compliance Management, Solution Test, and Service Execution.

This is an ongoing research and further results would be published shortly. 


\section{CONCLUSION}

Cloud computing is the fundamental change in technology at the moment. According to its many advantages such as on-demand self-service, broad network access, resource pooling, rapid elasticity or expansion, and measured service, Most organization are moved toward the cloud computing. Since this environment is conceived service-oriented and many IT services are provided to customer, service management and delivery of comprehensive architecture for this environment are important. To improve the management of services in cloud computing the proposed architecture is introduced.

IT service management frameworks and reference models such as PRM-IT, ITIL v3, HP, MOF, eTOM, COBIT5 are used to provide better services in different parts of this architecture. Operational support services section is composed of PRM-IT. eTOM's processes are used in business support services for billing \& revenue management and COBIT5's process govern ITSM of this architecture in Governce of IT section. In addition, few important cloud architecture are compared, the strengths of each have been obtained and deployed in proposed architecture.

At the same time, the relationship between processes of Operational support services and Governce of IT are shown in detail. Any section of this architecture is described with its processes in details. Four core cloud roles are defined. All of the processes in this architecture are important to implement complete ITSM in cloud, but Due to the constraints, some organization can not apply all the processes. So Five processes are introduced as fundamental and key of ITSM processes. Finally, the Processes that are involved in quality management are presented in last section. This processes ensures the quality of all IT products and services.

\section{REFERENCES}

[1] Böhm, M.; Leimeister, S.; Riedl, C.; Krcmar, H. 2009. Cloud computing: outsourcing 2.0 or a new business model for IT provisioning. In: Information Management \& Consulting, No. 24(2), pp. 6-14.

[2] Mell, Peter, and Timothy Grance. "The NIST definition of cloud computing (draft).2011." NIST special publication 800.145 .

[3] IBM Corporation, IBM Tivoli unified process.

[4] IBM Advisory Group.2011."Introduction and Architecture Overview IBM Cloud Computing Reference Architecture 2.0".

[5] Liu, F., Tong, J., Mao, J., Bohn, R., Messina, J., Badger, L., \& Leaf, D. 2011. NIST cloud computing reference architecture. NIST special publication, 500, 292

[6] ORACLE Advisory Group,2011. "Oracle® Reference Architecture".

[7] HP Advisory Group,2011. "Understanding the HP cloud System Reference Architecture".

[8] Cisco Advisory Group, 2009. "Cisco Cloud Computing - Data Center Strategy, Architecture, and Solutions".

[9] Koll, S. 2010, Kein Cloud Computing ohne IT Service Management. Positionspapier Cloud Computing und IT Service Management.

[10] Kopperger, D.; Kunsmann, J.; Weisbecker, A. 2009. IT-Servicemanagement. In: Handbuch ITManagement. Eds.: Tiemeyer, E. Carl Hanser Verlag, München 2009, pp. 126-263.

[11] Schwarzer, B.; Krcmar, H. 2010.Wirtschaftsinformatik, Schäffer-Poeschel Verlag, Stuttgart .

[12] OGC .2007. Service Strategy, TSO, Norwich (GB) 2007.

[13] Krcmar, H. 2010. Informationsmanagment, Springer, Berlin, Heidelberg.

[14] Böttcher, R. 2010. IT-Service-Management mit ITIL V3, Heise, Hannover.

[15] Böhm, M.; Leimeister, S.; Riedl, C.; Krcmar, H. 2009. Cloud computing: outsourcing 2.0 or a new business model for IT provisioning. In: Information Management \& Consulting. No. 24(2), pp. 6-14.

[16] Wischki, C. 2009. ITIL V2, ITIL V3 und ISO/IEC 20000, Cal Hanser Verlag, München, Wien.

[17] IBM Advisory Group,2008. PRM - IT IBM Process Reference Model for IT, IBM Corporation. 
[18] Pultorak, D., Henry, C., \& Leenards, P. 2008. MOF 4.0: Microsoft Operations Framework 4.0. Van Haren Publishing.

[19] ITSMRM, H. 2000. HP IT Service Management Reference Model. Technical White Paper. Palo Alto, California, USA: Hewlett-Packard Company. Accessed on Sptember.

[20] Arabalidousti, Fatemeh, and Ramin Nasiri.2013, Improving IT Service Management Architecture in Cloud Environment on Top of Current Frameworks. The International Conference on Digital Information Processing, E-Business and Cloud Computing (DIPECC2013). The Society of Digital Information and Wireless Communication.

[21] TM Forum Advisory Group,2012. "eTOM (Business Process Framework)”, TM Forum.

[22] Information Systems Audit, 2012. Control Association, \& Control Association. ISACA. COBIT5 Five: A Business Framework for the Governance and Management of Enterprise IT. ISACA.

[23] Wassermann, B.; Ludwig, H.; Laredo, J.; Bhattacharya, K.; Pasquale, L. 2009. Distributed crossdomain change management. Paper presented at the IEEE International Conference on Web Services, pp. 59-66.

[24] Pankesh Patel, Ajith Ranabahu, Amit Sheth . 2009. Service Level Agreement in Cloud Computing. (2009) No. 24(2), pp. 6-14.

[25] MOF Advisory Group. 2013. ” Problem management for reliable online services”,2013

\section{Authors}

1. Fatemeh arabalidousti was born in 1985 in Tehran (Iran) Where she received B.Sc in Computer software engineering from Dr. Shariaty University in 2011. She is studing M.Sc in Islamic Azad University, Central Tehran Branch from 2011 up to now. She has been working in business process improvement and system design field. She is interested in Cloud Architecture, Cloud Security, IT Service Management Frameworks (ITIL, PRM-IT, MOF, HP), Cloud Computing and Grid Computing. She published some papers in these fields.

2. Ramin Nassiri was born in 1967 in Tehran(Iran) where he receiced B.Sc in Computersoftware engineering from Tehran University in 1989. Later on he recived his M.Scand $\mathrm{PhD}$ in the same area in 2003. He joined to Islamic Azad University,Central Tehran Branch,College of Engineering since 2000 as a faculty member and is a full time assistant professor there.He is a member of editorial team of Internation journal of Computing intelligence, resarch and practices in SIU university,IL,USA. He has been managing a few Nation-wide and enterprise wide ICT project in a variety of ICT areas including ERP, Electronic Transactions, ITSM, Software testing and etc. He has been also managing well-known IT and

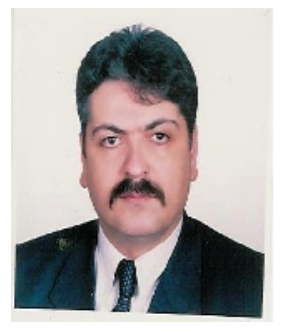
telecom companies since last 15 years onwards in Iran and UAE.

3. Mahsa Razavi Davoudi, Assistant Professor of Computer Engineering Department of Central Tehran Branch, Islamic Azad University of Iran. She has earned her Doctor of Philosophy at the Computer Engineering Department, Science and Research Branch, Islamic Azad University of Iran. Her research interests are Enterprise Architecture, Software Architecture, Service-oriented Architectures, Cloud Computing, Quality attributes, Assessment methods and Decision making. 